\title{
Margin Tata Niaga Cumi-Cumi di Koperasi Mina Fajar Sidik Kecamatan Blanakan Kabupaten Subang
}

\author{
[Squid Registration Margin at Mina Fajar Sidik Cooperative \\ District Blanakan Subang Regency] \\ Paidi \\ Jurusan Penyuluhan Perikanan - Sekolah Tinggi Perikanan \\ Jalan Cikaret Nomor 2 Bogor, Jawa Barat \\ Diterima: 07 Januari 2016; disetujui: 22 Maret 2016
}

\begin{abstract}
Abstrak
Penelitian ini bertujuan untuk mengetahui struktur pasar, margin dan efisiensi tataniaga ikan cumicumi di TPI KUD Mandiri Mina Fajar Sidik, Kecamatan Belanakan, Kabupaten Subang, Jawa Barat. Penelitian dilakukan dengan metode deskriptif serta dilakukan dengan studi kasus, dari bulan juni-juli 2014. Data yang diambil berupa data primer dan data sekunder. Sasaran diambil secara porposional yang terdiri dari TPI KUD Mandiri mina fajar sidik (saluran I), pedagang pengumpul, (saluran II) dan pedagang pengecer (saluran III). Pengolahan data dilakukan dengan kuantitatif maupun pendekatan kualitatif. Struktur pasar berupa pasar heterogen, dalam hal ini KUD Mandiri sebagai penentu harga paling kuat. Hal ini berdampak pada besarnya margin yang berbeda-beda, akibat dari struktur dan perilaku pasar, sehingga berakibat keuntungan yang tidak merata atau tidak efisien.
\end{abstract}

Kata kunci: efisien, margin, pedagang, struktur pasar, tataniaga.

\begin{abstract}
This study aims to determine the market structure, margin and efficiency of squid fish trade in TPI KUD Mandiri Mina Fajar Sidik, District Belanakan, Subang Regency, West Java. The research was conducted by descriptive method and conducted by case study, from June to July 2014. The data taken are primary data and secondary data. Targets are taken porposional consisting of TPI KUD Mandiri Mina Fajar Sidik (channel I), collecting traders, (channel II) and retailers (channel III). Data processing is done by quantitative as well as qualitative approach. The market structure is heterogeneous market, in this case KUD Mandiri as the most powerful price determinant. This has an impact on the amount of different margins, resulting from market structure and behavior, resulting in uneven or inefficient profits.
\end{abstract}

Keywords: efficient, margin, merchant, market structure, trader.

\section{PENDAHULUAN}

Perikanan menurut Undang-Undang Nomor 13 Tahun 2014 Tentang Perikanan, pengertian dari perikanan adalah semua kegiatan yang berhubungan dengan pengelolaan pemanfaatan sumber daya ikan dan lingkungannya mulai dari pra-

\footnotetext{
$\triangle$ Penulis korespondensi

Alamat surel: paidi.bogor@gmail.com
}

produksi, produksi, pengolahan sampai dengan pemasaran, yang dilaksanakan alam suatu system bisnis perikanan.

Guna pemenuhan kebutuhan jasmani bagi konsumen yang berada jauh dari masyarakat pantai, maka sudah barang tentu diperlukan beberapa fungsi Tataniaga (Pemasaran) antara lain: 
1). Fungsi untuk pertukaran (exchanged function), meliputi aspek: pembelian dan penjualan.

2). Fungsi fisik (fhysical function), meliputi aspek-aspek: pengangkutan, penyimpanan, dan pengolahan.

3). Fungsi dari penunjang (facilitating function), meliputi berbagai aspek: standardisasi termasuk juga gradasi, pembiayaaan serta pembelanjaan, penangungan risiko, pengumpulan, penafsiran, dan penyebaran informasi

Berdasarkan fungsi fisik tersebut di atas dimana salah satunya adalah tentang pengangkutan (transportation), maka dalam mendistribusikan hasil perikanan tentunya memerlukan berbagai perlakuan supaya produk hasil perikanan yang sampai ketangan konsumen, mutu masih terjamin. Perlakuan tersebut tentunya membutuhkan biaya. Semakin banyak perlakuan, maka semakin tahan hasil perikanan tersebut, sehingga rantai Tataniaga (Pemasaran) bisa semakin jauh dan menyebabkan saluran Tataniaga (Pemasaran) bertambah panjang. Biayabiaya yang akan dikeluarkan tersebut akan mempengaruhi suatu harga jual kepada konsumen, sehingga berpengaruh terhadap marjin produk hasil perikanan tersebut.

Berdasarkan latar belakang di atas, maka rumusan permasalahnya adalah bagaimana struktur dan efisiensi tataniaga (pemasaran) Ikan Cumi-cumi di TPI KUD Mandiri Mina Fajar Sidik, Kecamatan Blanakan, Kabupaten Subang Provinsi Jawa Barat.

Tujuan dari penelitian ini adalah untuk mengetahui struktur dan efisiensi tataniaga (pemasaran) Ikan Cumi.cumi di TPI KUD Mandiri Mina Fajar Sidik Desa Blanakan pada Kecamatan Blanakan, Kabupaten Subang Provinsi Jawa Barat.

Tataniaga (pemasaran) suatu hasil perikanan adalah mencakup segala kegiatan dan usaha yang berhubungan dengan perpindahan hak milik dan fisik barang-barang hasil perikanan dan kebutuhan usaha perikanan dari tangan produsen ke tangan konsumen, termasuk di dalamnya kegiatan-kegiatan tertentu yang menghasilkan perubahan bentuk dari berbagai barang yang ditujukan untuk lebih mempermudah penyalurannya dan memberikan kepuasan yang lebih tinggi kepada konsumennya.

Menurut Kohl dan Downey (1972), Tataniaga mencakup segala pekerjaan dan badan-badan yang akan terlibat dalam pemindahan hasil-hasil perikanan dari pembudidaya/nelayan termasuk dari hasilhasil yang berasal dari hasil perikanan sampai ke tangan konsumen akhir. Tataniaga adalah suatu keragaan (performance) semua usaha mencakup kegiatan arus barang/jasa mulai dari titik 
usahatani sampai di tangan konsumen akhir.

Tataniaga juga mencakup segala pekerjaan termasuk badan-badan yang menyelenggarakannya yang terlibat dalam pemindahan hasil-hasil perikanan dari pembudidaya/nelayan termasuk dari hasilhasil yang berasal dari hasil perikanan sampai ke tangan konsumen. Tataniaga adalah suatu keragaan (performance) semua usaha mencakup kegiatan arus barang/jasa mulai dari titik usahatani sampai di tangan konsumen akhir (Tomek dan Robinson, 1977).

Golongan produsen adalah mereka yang tugas utamanya menghasilkan barang-barang. Disamping berproduksi, golongan ini seringkali aktif melaksanakan beberapa fungsi tataniaga tertentu untuk menyalurkan hasil produksinya kepada konsumen. Pedagang pengumpul atau pedagang penampung adalah merupakan pedagang yang menerima secara langsung ataupun tidak langsung dari pembudidaya atau nelayan. Pedagang besar (wholesaler) memperdagangkan barang dalam jumlah lebih besar. Pedagang ini aktif di pasarpasar pusat dan akan memperoleh barang terutama dari pengumpul lokal. Pedagang pengecer adalah perantara yang menjual barang-barang dalam jumlah kecil secara langsung kepada unit konsumen akhir (household-consumer). Biasanya para pedagang ini menerima barang dari pedagang besar, pedagang pengumpul atau dari produsen.

Lembaga pemberi suatu jasa adalah mereka yang memberi jasa atau fasilitas untuk memperlancar fungsi tataniaga yang dilakukan oleh produsen atau pedang perantara. Contoh dari lembaga ini antara lain: unit bank, unit usaha pengangkutan (perusahaan kereta api, truk, kapal laut dan penerbangan), biro iklan dan sebagainya.

Saluran tataniaga (pemasaran) adalah suatu perangkat organisasi yang saling tergantung dalam menyediakan satu produk atau jasa yang digunakan atau dikonsumsi oleh konsumen atau pengguna unit bisnis (Kotler \& Amstrong, 1992). Sedangkan menurut Manulang (1994) saluran tataniaga (pemasaran) adalah saluran pemindahan pemilikan barang dari produsen sampai kepada konsumen

Secara teori, suatu marjin tataniaga (pemasaran) dapat didefinisikan sebagai perbedaan harga yang dibayarkan oleh konsumen dengan harga yang diterima oleh produsen. Marjin tataniaga dapat juga dinyatakan sebagai nilai-nilai dari jasa-jasa pelaksanaan kegiatan tataniaga sejak dari produsen hingga tingkat konsumen akhir. Menurut Dahl \& Hammond (1977), Marjin Tataniaga (pemasaran) adalah harga yang terjadi di tingkat produsen dgn tingkat konsumen. 
Marjin adalah suatu istilah yang digunakan untuk menyatakan perbedaan harga yang dibayar pada penjual pertama dan harga yang dibayar oleh pembeli terakhir. Azzaino (1983), mendefinisikan bahwa marjin tataniaga (pemasaran) adalah sebagai perbedaan harga yang dibayar oleh konsumen paling akhir dengan harga yang diterima oleh produsen untuk produk yang sama. Marjin tataniaga ini termasuk semua ongkos untuk dapat menggerakan produk tersebut dimulai dari unit produsen (pembudidaya/nelayan) sampai ke tangan konsumen akhir. Jadi dalam proses analisis pada marjin tataniaga harus didasarkan pada kondisi yang sama dan kondisi struktur pasar bersaing sempurna. Marjin tataniaga merupakan konsep penting digunakan dalam menganalisis efisiensi tataniaga.
Marjin tataniaga (pemasaran) terdiri dari biaya pemasaran dan keuntungan pembagian pemasaran. Secara matematis besarnya Marjin Tataniaga di rumuskan sebagai berikut :

$$
\begin{aligned}
& \mathrm{P}_{\mathrm{ki}}-\mathrm{P}_{\mathrm{pi}}=\mathrm{M}_{\mathrm{i}} \\
& \mathrm{C}_{\mathrm{i}}+\pi_{\mathrm{i}}=\mathrm{M}_{\mathrm{i}}
\end{aligned}
$$

Dimana :

$\mathrm{M}_{\mathrm{i}}=$ Marjin tataniaga (Pemasaran) di Lembaga Tataniaga (Pemasaran) ke-i

$\mathrm{P}_{\mathrm{ki}}=$ Harga jual di Lembaga tataniaga (pemasaran) ke-i

$\mathrm{P}_{\mathrm{pi}}=$ Harga Beli di Lembaga tataniaga (pemasaran) ke-i

$\mathrm{C}_{\mathrm{i}}=$ Biaya di Lembaga tataniaga (pemasaran) ke-i

$\pi_{\mathrm{i}}=$ Keuntungan di Lembaga tataniaga (pemasaran) ke-i

Dengan demikian total marjin tataniaga (pemasaran) (M) adalah :

$$
\begin{aligned}
\mathrm{M}^{\mathrm{n}} & =\sum \mathrm{M}_{\mathrm{i}} \\
\mathrm{i} & =1
\end{aligned}
$$

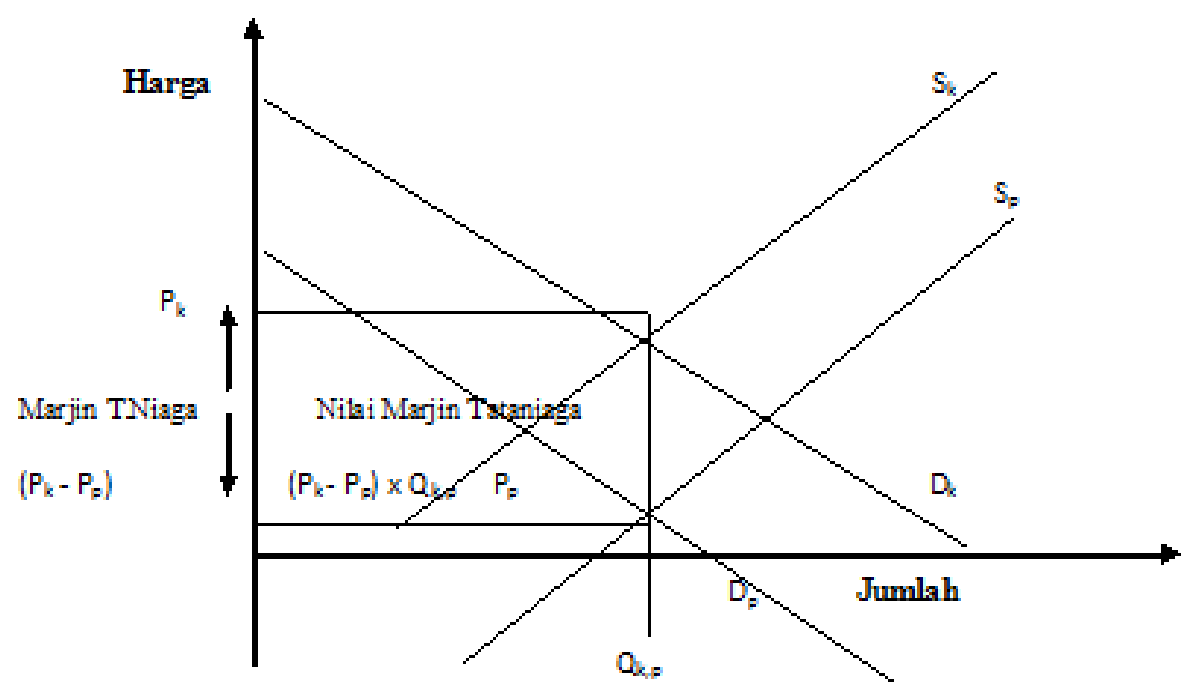

Gambar 1. Marjin Tataniaga (Pemasaran)

Keterangan :

$\mathrm{P}_{\mathrm{k}} \quad=$ Harga di tingkat Konsumen

(Ped. Perantara)
$\mathrm{P}_{\mathrm{p}} \quad=$ Harga di tingkat Produsen (Petani/Pembudidaya)

$\mathrm{S}_{\mathrm{p}} \quad=$ Kurva penawaran di tingkat 


\author{
Produsen (Pembudidaya) \\ $\mathrm{S}_{\mathrm{r}} \quad=$ Kurva penawaran di Tingkat \\ Konsumen (Ped. Perantara) \\ $\mathrm{D}_{\mathrm{p}} \quad=$ Kurva permintaan di tingkat \\ Produsen (Petani/Pembudidaya) \\ $\mathrm{D}_{\mathrm{k}} \quad=$ Kurva permintaan di Tingkat \\ Konsumen (Ped. Perantara) \\ $\begin{aligned} \mathrm{P}_{\mathrm{k}}-\mathrm{P}_{\mathrm{p}}= & \text { Marjin Tataniaga, }\left(\mathrm{P}_{\mathrm{k}}-\mathrm{P}_{\mathrm{p}}\right) \times \mathrm{Q}_{\mathrm{k}, \mathrm{p}} \\ & \text { Nilai Marjin Tataniaga }\end{aligned}$ \\ Umumnya suatu marjin tataniaga
} (pemasaran) bersifat relatif kurang fleksibel/tidak banyak berubah, misalnya harga jual ikan tetap naik akan tetapi biaya/ongkos pemasaran tidak, maka keuntungan yang diterima oleh produsen akan lebih besar. Marjin tataniaga (pemasaran) yang tinggi menunjukkan belum efisiensinya suatu unit tataniaga (pemasaran) dan hal tersebut disebabkan oleh biaya atau ongkos pemasaran (yang tetap) sehingga kepuasan konsumen berkurang. Apabila tingginya marjin akibat derajat pengolahan semakin tinggi, yang mengakibatkan kepuasan konsumen bertambah maka dianggap pemasaran lebih efisien.

Menurut Tomek dan Robinson (1977), Marjin Tataniaga (Pemasaran) terdiri atas dua bagian, yaitu:

1. Marjin suatu Tataniaga (Pemasaran) merupakan perbedaan harga antara harga yang dibayar konsumen dengan harga yang diterima oleh produsen.

2. Marjin suatu Tataniaga (Pemasaran) merupakan biaya dari jasa-jasa yang dibutuhkan sebagai akibat permintaan dan atau penawaran dari jasa-jasa pemasaran tersebut. Pada artinya penentuan harga ditetapkan melalui pelaksanaan fungsi permintaan dan penawaran kepada seluruh kondisi pasar. Pelayanan pasar ini mencakup pengumpulan, termasuk juga kegiatan pengolahan, transportasi sampai pengeceran, sehingga pada dasarnya marjin tataniaga (Pemasaran) sangat tergantung pada tingkat permintaan dan penawaran dari suatu jasa pasar tersebut.

Menurut Nasruddin (1999), suatu marjin kegiatan tataniaga (Pemasaran) menggambarkan perbedaan harga yang dibayarkan konsumen dan harga yang diterima petani, termasuk dalam marjin tersebut adalah seluruh biaya Tataniaga (Pemasaran) (marketing cost) dan keuntungan (marketing profit) yang dikeluarkan oleh lembaga tataniaga (Pemasaran) mulai dari pintu gerbang pembudidaya sampai kepada konsumen (rantai Tataniaga/Pemasaran).

Komponen unit marjin Tataniaga (Pemasaran) terdiri dari: (1) biaya-biaya yang juga diperlukan lembaga-Lembaga Tataniaga (Pemasaran) untuk melakukan fungsi-fungsi pemasaran yang disebut biaya pemasaran atau biaya fungsional (functional cost) dan (2) keuntungan (profit) dari suatu lembaga Tataniaga (Pemasaran) (Sudiyono, 2002). 
Menurut Kotler \& Keller (2006) definisi tentang biaya tataniga (pemasaran) adalah biaya-biaya yang dikeluarkan dalam proses pengaliran komoditas dari produsen sampai ke konsumen. Nilai tentang biaya Tataniaga (Pemasaran) tergantung dari keadaan lembaga Tataniaga (Pemasaran) yaitu ditinjau dari aktivitas lembaga-lembaga yang terlibat serta adanya fasilitasfasilitas, sedangkan keuntungan kepada lembaga suatu Tataniaga (Pemasaran) merupakan penerimaan yang diperoleh lembaga sebagai bagian imbalan dari menyelenggarakan semua fungsi-fungsi Tataniaga (Pemasaran).

Adanya perbedaan kegiatan dari setiap lembaga akan menyebabkan harga jual antara lembaga satu dengan lembaga yang lain sampai tingkat konsumen akhir. Semakin banyak lembaga Tataniaga (Pemasaran) yang terlibat dalam penyaluran suatu komoditas dari titik produsen sampai ke titik konsumen, maka akan semakin besar perbedaan harga komoditas tersebut di titik produsen dibandingkan harga yang dibayar oleh konsumen. Perbedaan harga inilah yang disebut dengan marjin Tataniaga (Pemasaran). Hal ini dapat dimengerti karena semakin banyak lembaga Tataniaga (Pemasaran) yang terlibat, maka akan semakin banyak pula perlakuan yang diberikan terhadap komoditas tersebut sehingga menimbulkan kenaikan biaya Tataniaga (Pemasaran). Biaya untuk Tataniaga (Pemasaran) yang meningkat tersebut tentunya akan mendorong pengambilan keuntungan yang lebih besar dilakukan oleh masing-masing lembaga Tataniaga (Pemasaran) yang terlibat dalam proses penyaluran komoditas tersebut.

Konsep marjin ini berguna untuk mengetahui porsi harga yang berlaku di tingkat konsumen yang dinikmati oleh petani. Besar kecilnya marjin Tataniaga (Pemasaran) sering digunakan sebagai kriteria untuk penilaian apakah pasar tersebut sudah efisien.

\section{Keadaan Umum Cumi-Cumi di Indonesia}

Pertumbuhan kepemilikan alat tangkap jenis jaring cumi dapat dikatakan statis dari tahun 2009 sampai 2012. Pada tahun 2013 jaring cumi mengalami peningkatan sebesar 48,39\% (Koentjoroningrat. 1993). Komposisi jenis makanan pada Loligo edulis dan Sepia officinalis didominasi oleh ikan dan udang sedangkan untuk Sepioteuthis lessoniana hampir seluruh lambung yang dijumpai jenis makanan adalah ikan. Dengan demikian ketiga jenis cumi yang diteliti bersifat karnivora dengan ikan sebagai makanan utamanya (Omar, 
2002). Unsur mineral mikro yang terukur pada contoh cumi-cumi dan udang vannamei adalah $\mathrm{Zn}$ dan $\mathrm{I}$, sedangkan $\mathrm{Cu}$ dan $\mathrm{Fe}$ tidak terdeteksi. Kelarutan mineral Calsium dan Zn meningkat setelah perebusan, terutama pada perebusan selama 20 menit dengan menggunakan suatu asam asetat 0,5\% (Nurjanah dkk, 1999).

\section{BAHAN DAN METODE}

Penelitian dilakukan di Tempat Pelelangan Ikan (TPI) KUD Mina Fajar Sidik Kecamatan Blanakan Kabupaten Subang Jawa Barat pada Bulan Juni Juli 2014.

Penelitian menggunakan metode deskriptif dengan jenis penelitian studi kasus. Data yang dikumpulkan dalam penelitian ini adalah data primer dan data sekunder. Data primer diperoleh dari para pedagang melalui wawancara kepada para kelompok pelaku Tataniaga (Pemasaran). Data-data primer yang dikumpulkan terdiri atas "data identitas" dan "data usaha" yang meliputi:

I. Data Identitas: Nama, umur, jenis kelamin,jumlah keluarga, tingkat pendidikan

II. Data Usaha: Jenis usaha, lama usaha, kepemilikan usaha, jenis komoditi, harga, sistem penjualan dan jenis biaya yang dikeluarkan.
Sedangkan data sekunder diperoleh dari Tempat Pendaratan Ikan KUD Mina Fajar Sidik, Perpustakaan, dan internet.

Teknik pengambilan contoh yang digunakan adalah Purposive Sampling, yaitu peneliti secara sengaja memilih atau menentukan serta mewawancarai 10 orang pedagang Ikan Cumi-cumi yang terdiri atas nelayan sebagai produsen, TPI KUD Mina Fajar Sidik, pedagang pengumpul, dan pedagang pengecer.

Data dan juga informasi yang dikumpulkan serta dianalisis dengan menggunakan pendekatan kuantitatif dan kualitatif. Pendekatan kuantitatif dilakukan jika ciri-ciri dari suatu fakta sosial dapat dinilai dengan angka-angka. Sedangkan suatu pendekatan kualitatif dilakukan jika ciri-ciri dari suatu fakta sosial tidak dapat diutarakan dalam angka-angka, tetapi didalam bentuk atau suatu format kategori (Koentjoroningrat, 1993).

Kabupaten Subang memiliki luas wilayah sebesar 205.176,95 Ha, dengan 254 desa dan 30 kecamatan. Wilayah kabupaten dapat di bagi ke dalam tiga zona, yaitu :

1. Daerah Pegunungan (Subang bagian selatan).

Daerah ini memiliki katinggian antara 500-1500 m dpl dengan luas 41.035,09 hektar atau 20 persen dari 
seluruh luas wilayah Kabupaten Subang. Wilayah ini meliputi Kecamatan: Ciater Serangpanjang, Jalancagak, sebagaian Kasomalang, Sagalaherang, sebagian besar Kecamatan Jalancagak dan sebagian besar Kecamatan Tanjungsiang.

2. Daerah Berbukit dan Dataran (Subang bagian tengah)

Daerah dengan ketinggian antara 50 - $500 \mathrm{~m}$ dpl dengan luas wilayah 71.502,16 hektar atau 34,85 persen dari seluruh luas wilayah Kabupaten Subang. Zona ini meliputi wilayah Kecamatan Cijambe, Subang, Cibogo, Cipeundeuy, Kalijati, Dawuan, sebagian besar Kecamatan Purwadadi, Cikaum dan Pagaden Barat.

3. Daerah Dataran Rendah (Subang bagian utara)

Dengan ketinggian antara 0-50 m dpl dengan luas 92.639,7 hektar atau 45,15 persen dari seluruh luas wilayah Kabupaten Subang. Wilayah ini meliputi Kecamatan Pagaden, Cipunagara, Compreng, Ciasem, Pusakanagara, Sukasari, Pusakajaya Pamanukan, Legonkulon, Blanakan, Patokbeusi, Tambakdahan, sebagian Pagaden Barat.

Iklim dapat dilihat dari tingkat kemiringan lahan, sekitar $80.80 \%$ wilayah Kabupaten memiliki tingkat kemiringan $00-170,10.64 \%$ dengan tingkat kemiringan 180 - 450 sedangkan sisanya $(8.56 \%$ memiliki kemiringan di atas 450). Secara umum wilayah Kabupaten Subang beriklim tropis, dalam tahun 2005 curah hujan rata-rata pertahun $2.352 \mathrm{~mm}$ dengan jumlah hari hujan 100 hari.

Dengan iklim yang demikian, serta ditunjang oleh adanya lahan yang subur dan banyaknya suatu aliran sungai, menjadikan sebagian besar luas tanah Kabupaten Subang digunakan untuk perikanan. Desa Blanakan merupakan salah satu desa dari sembilan desa yang ada di Kecamatan Blanakan di bawah naungan Kabupaten Subang, Provinsi Jawa Barat. Secara Geografis, Desa Blanakan terletak di bagian paling utara dari Jawa Barat, antara $6^{\circ} 10^{\prime}-6^{\circ} 22^{\prime}$ lintang selatan dan $107^{\circ} 30^{\prime}-107^{\circ} 53^{\prime}$ bujur timur. Desa Blanakan terletak sekitar 46,03 km dari ibukota Kabupaten Subang yang dapat ditempuh dengan motor atau mobil selama 1 jam 30 menit. Jarak ke ibu kota provinsi (Bandung) 90 km dan jarak ke ibukota negara (DKI Jakarta) 210 km. Desa Blanakan sebagai lokasi sasana karya adalah desa dengan luas wilayah 980,436 $\mathrm{Ha}$, yang digunakan untuk lahan sawah, ladang, pemukiman, hutan, serta fasilitas umum seperti jalan, lapangan, dan perkantoran 
pemerintah. Pola penggunaan tanah di kawasan Desa Blanakan sebagian besar digunakan untuk sawah teknis yaitu sebesar 434,065 Ha, untuk pemukiman 156,329 Ha dan hutan lindung seluas 151,804 Ha.

Untuk jumlah penduduk di Desa Blanakan terdiri dari jumlah penduduk laki-laki sebesar 5.388 orang $(50.5 \%)$ dan penduduk berjenis kelamin perempuan tercatat sebesar 5.270 orang (49.44\%). Seluruh jumlah penduduk ini menyebar dalam setiap dusun dengan jumlah kepala keluarga $3.658 \mathrm{KK}$ dan kepadatan penduduk Desa Blanakan adalah 14,67 per $\mathrm{km}^{2}$. Berdasarkan perbandingan gender dan usia, maka tersedia banyak tenaga kerja produktif yang dapat mendukung pengembangan sistem agribisnis dan pembangunan di Desa Blanakan. Jumlah penduduk lakilaki yang relatif sebanding dengan jumlah relatif penduduk perempuan menunjukkan bahwa di Desa Blanakan terdapat pembagian tugas atau pekerjaan yang merata, misalnya laki-laki banyak menjadi nelayan dan buruh tani, sedangkan tenaga kerja perempuan banyak menjadi buruh tani dan tenaga kerja pada usaha yang bergerak di bidang perikanan.

Potensi agribisnis di area Desa Blanakan terdiri dari potensi tanaman, ternak, dan perikanan. Berdasarkan potensi tersebut, perikanan merupakan potensi terbesar bagi Desa Blanakan. Pada tahun 2013 berdasarkan data yang diperoleh dari desa dan Dinas Perikanan Subang, ikan laut yang paling banyak ditangkap adalah Cumi-cumi yaitu masing-masing sebanyak 300 ton, layur sebanyak 290 ton, kakap 284 ton, tenggiri 225 ton, dan sisanya ikan cucut, tongkol, belanak, dan lainnya.

Keberhasilan dari Desa Blanakan menjadi desa produksi ikan laut tidak terlepas dari peranan dari lembaga desa khususnya Koperasi Unit Desa (KUD) Inti Mina Fajar Sidik. KUD mengelola anggotanya yang terdiri dari nelayan dan bakul dengan baik melalui Tempat Pelelangan Ikannya (TPI). Selama tahun 2013, kontribusi anggota terhadap produksi di TPI KUD Mandiri Mina Fajar Sidik adalah sebesar 2,95 persen dan sisanya sebesar 97,05 persen didominasi oleh nelayan pendatang.

Dari tahun ke tahun jumlah produksi perikanan tangkap di Desa Blanakan terus menurun. Banyak faktor yang mengakibatkan keadaan tersebut terjadi, diantaranya adalah keadaan laut yang sudah tidak memungkinkan ikan untuk berkembang biak dengan baik karena polusi dan pencemaran laut yang terjadi. Selain itu alat tangkap yang 
masih masih sederhana menjadi salah satu faktor rendahnya hasil tangkap para nelayan.

\section{HASIL DAN PEMBAHASAN}

Jumlah responden yang terpilih dalam penelitian ini adalah 10 orang responden yang menjual Ikan Cumicumi, terdiri atas: 5 orang Pedagang Pengumpul Lokal/Supplier dan 5 orang Pedagang Pengecer. Hasil wawancara disajikan dalam bentuk tabulasi seperti tertuang dalam Lampiran 1.

Struktur pasar Ikan Cumi-cumi yang ada di daerah penelitian dianalisis berdasarkan beberapa faktor pemasaran diantaranya: 1). Lembaga dan saluran pemasaran, dan 2). Sifat kekhasan produk (product differentiation).

Lembaga Tataniaga (Pemasaran) yang terlibat dalam pemasaran Ikan Cumi-cumi ini meliputi: Produsen (Nelayan), Pedagang Pengumpul I (PP 1) dalam hal ini TPI KUD Mandiri Mina Fajar Sidik, Pedagang Pengumpul II (PP II) yaitu Supplier, dan Pedagang Pengecer, serta Konsumen. Ikan Cumicumi yang dijual pembudidaya per periode sebagai berikut: dari total $100 \%$ penjualan ke dalam 3 saluran pemasaran I, II, dan III dengan rincian $60 \%, 30 \%$, dan $10 \%$. Adapun ketiga saluran dimaksud dapat dilihat pada Gambar 4. $\underline{\text { Saluran tataniaga (pemasaran) I : }}$

Berdasarkan Gambar 4,Produsen (Para Nelayan) menyerahkan seluruh hasil tangkapannya kepada TPI KUD Mandiri Mina Fajar Sidik MFS (TPI KUD MMFS) untuk dilelang, dan Pedagang Pengumpul II (Supplier) merupakan pihak pertama yang melakukan kegiatan transaksi jual beli Ikan Cumi-cumi sebesar $60 \%$ dan selanjutnya disalurkan ke Pedagang Pengecer dan terakhir kepada Konsumen Dalam Negeri (DN).

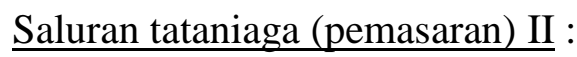

Pada saluran pemasaran II, Pedagang Pengecer merupakan pihak pertama yang melakukan kegiatan transaksi jual beli Ikan Cumi-cumi sebesar $30 \%$ dari TPI KUD Mandiri Mina Fajar Sidik MFS (TPI KUD MMFS) dan selanjutnya disalurkan terakhir kepada Konsumen Dalam Negeri (DN).

Saluran tataniaga (pemasaran) III :

Pada saluran pemasaran III, Exportir (PT. Samudra) merupakan pihak pertama yang melakukan kegiatan transaksi jual beli Ikan Cumi-cumi sebesar $10 \%$ dan selanjutnya disalurkan terakhir kepada Konsumen Luar Negeri (LN) 
$100 \%$

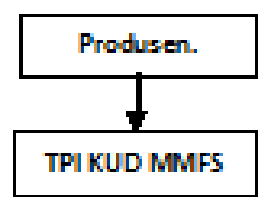

(III)

$30 \%$

(I)

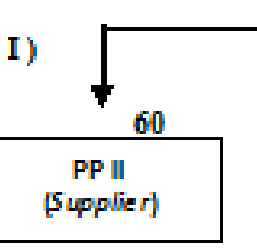

$30 \%$

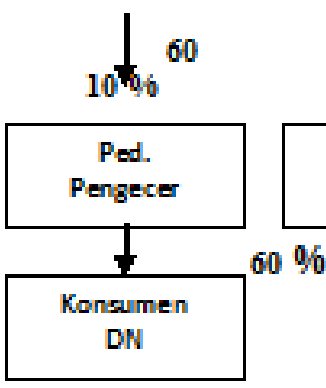

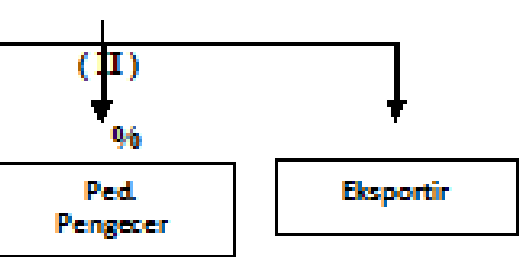

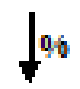

Konsumen

DN

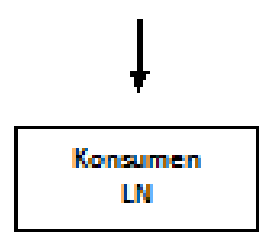

Gambar 4. Saluran Tataniaga (Pemasaran) Ikan Cumi-cumi di TPI KUD Mandiri Mina Fajar Sidik Subang

Berdasarkan tiga saluran tataniaga (pemasaran) pada Gambar 4, maka konfigurasi pasar yang terjadi adalah bahwa Supplier, Pedagang Pengecer maupun Exportir berperan sebagai penerima harga (price taker). Dengan demikian maka struktur pasar Ikan Cumicumi yang terjadi di TPI KUD Mandiri Mina Fajar Sidik adalah pasar persaingan tidak sempurna (imperfect competitive market).

\section{Sifat Kekhasan Produk (Product Differentiation)}

Selain jumlah dan ukuran pasar, salah satu cara untuk mengukur struktur pasar adalah melalui sifat kekhasan produk (product differentiation). Differensiasi adalah tindakan merancang serangkaian keunikan yang bermakna untuk membedakan tawaran perusahaan dengan para pesaingnya. Setiap perusahaan cenderung membuat produk-produknya berbeda dengan para pesaingnya.

Berdasarkan hasil data yang diperoleh, Ikan Cumi-cumi yang diperjual belikan TPI KUD Mandiri Mina Fajar Sidik cukup bervariasi harganya sesuai ukuran sizenya. Hal ini mengindikasikan bahwa kondisi atau keadaan produk Ikan Cumi-cumi bersifat heterogen. Jika didasarkan penggolongan struktur pasar, maka struktur pasar Ikan Cumi-cumi yang ada di TPI KUD Mandiri Mina Fajar Sidik adalah pasar persaingan tidak sempurna. 


\section{Analisis Perilaku Pasar}

Perilaku pasar merupakan pola tingkah laku berbagai lembaga-Lembaga Tataniaga (Pemasaran) dalam struktur pasar tertentu. Perilaku pasar dapat dilihat dari beberapa faktor diantaranya: 1) Penentuan harga dan Stabilitas pasar, dan 2) Praktek-praktek dalam menjalankan fungsi-fungsi tataniaga (pemasaran).

\section{Penentuan Harga dan Stabilitas Pasar}

Harga merupakan salah satu faktor yang menormalisasikan kegiatan suatu pemasaran di daerah produsen. Dengan struktur pasar persaingan tidak sempurma (imperfect competitive market) yang terjadi di TPI KUD Mandiri Mina Fajar Sidik, maka hal ini membuat TPI KUD Mandiri Mina Fajar Sidik yang berperan sebagai produsen berada pada posisi tawar menawar (bargaining position) yang kuat dalam menentukan harga. Hal ini karena pendistribusian informasi yang bersifat simetris, dimana TPI KUD Mandiri Mina Fajar Sidik berada pada posisi sebagai penentu harga.

\section{Praktek-Praktek dalam Menjalankan Fungsi Tataniaga (Pemasaran)}

Fungsi darai tataniaga (pemasaran) merupakan proses penyampaian produk (barang/jasa) dari tingkat produsen ke tingkat konsumen yang memerlukan berbagai kegiatan atau tindakan yang dapat memperlancar proses penyampaian produk yang bersangkutan. Terkait dengan definisi tersebut, maka perilaku pasar merupakan pencerminan dari keputusan-keputusan yang diambil dari lembaga-Lembaga Tataniaga (Pemasaran) dalam menghadapi struktur pasar yang berlaku. Perilaku pasar ini dapat dilihat dari praktek-praktek yang dilakukan oleh unit lembaga tataniaga (pemasaran) dalam menjalankan fungsifungsi tataniaga (pemasaran) yang juga merupakan strategi bagi para Lembaga Tataniaga (Pemasaran) dalam memperoleh keuntungan yang sebesar-besarnya. Dalam pelaksanaan penelitian, praktek-praktek dalam menjalankan fungsi-fungsi tataniaga (pemasaran) yang dilakukan oleh TPI KUD Mandiri Mina Fajar Sidik dan lembaga-lembaga tataniaga (pemasaran) lainnya adalah fungsi pertukaran, fungsi fisik dan fungsi fasilitas.

Fungsi pertukaran terdiri atas kegiatan penjualan dan pembelian. Fungsi ini dilakukan oleh semua pedagang kecuali produsen (nelayan) atau TPI KUD Mandiri Mina Fajar Sidik yang hanya melakukan kegiatan penjualan. Transaksi penjualan antara TPI KUD Mandiri Mina Fajar Sidik dengan Supplier, Pedagang Pengecer, dan Exportir dilakukan langsung, dimana para pedagang tersebut membeli produk Ikan Cumi-cumi secara langsung kepada TPI KUD Mandiri Mina Fajar Sidik. 
Tabel 2. Fungsi - Fungsi Tataniaga (Pemasaran) yang Dilakukan oleh Masing-masing Lembaga Tataniaga (Pemasaran) Ikan Cumi-cumi di TPI KUD Mandiri Mina Fajar Sidik Subang.

\begin{tabular}{llcccc}
\hline No. & \multicolumn{1}{c}{ Fungsi Pemasaran } & $\begin{array}{c}\text { TPI KUD } \\
\text { M MFS }\end{array}$ & Supplier & $\begin{array}{c}\text { Pedagang } \\
\text { Pengecer }\end{array}$ & Exportir \\
\hline 1. & Fungsi Pertukaran : & & & & \\
& a. Pembelian & - & + & + & + \\
b. Penjualan & + & + & + & + \\
2. Fungsi Fisik: & a. Pengangkutan & - & + & + & + \\
& b. Pengemasan & - & + & + & + \\
c. Penyimpanan & - & + & + & + \\
Fungsi Fasilitas : & - & + & + & + \\
& a. Sortasi & + & + & + & + \\
& b. Grading & - & + & + & + \\
& c. Penanggungan resiko & & + & + & + \\
\hline d. Informasi Harga & & + & + & + & +
\end{tabular}

Sumber : Data Hasil Olahan, 2014

Keterangan : + = melakukan fungsi pemasaran - = tidak melakukan fungsi pemasaran

Adapun alasan dilakukannya pembelian langsung dari TPI KUD Mandiri Mina Fajar Sidik ini adalah karena harganya lebih murah dengan kualitas yang masih baik.

Fungsi tataniaga (pemasaran) lainnya yang dilakukan oleh masingmasing lembaga tataniaga (pemasaran) adalah fungsi fisik dan fungsi fasilitas. Fungsi fisik terdiri atas kegiatan pengangkutan / transportasi, pengemasan / packing, serta penyimpanan, sedangkan fungsi fasilitas terdiri atas kegiatan: sortasi, grading, penanggungan resiko dan informasi harga. Secara rinci peran yang dilakukan oleh setiap lembaga tataniaga (pemasaran) Ikan Cumi-cumi di daerah penelitian dapat dilihat pada Tabel 2 .

Bagi TPI KUD Mandiri Mina Fajar Sidik yang berfungsi sebagai produsen, fungsi fasilitas seperti "informasi harga" yang merupakan bagian dari sistem informasi pasar, adalah sesuatu yang sangat penting. Hal ini terkait dengan kedudukannya sebagai satu-satunya layanan pendukung perikanan yang sangat dibutuhkan. Dengan demikian informasi pasar khususnya informasi tentang Ikan Cumi-cumi mutlak diperlukan secara terus menerus, karena sistem informasi adalah suatu struktur yang berkesinambungan dan saling berinteraksi dari orang-orang, peralatan dan juga prosedur untuk: mengumpulkan, mensortir, menganalisis, mengevaluasi, dan juga mendistribusikan informasi yang dibutuhkan secara tepat waktu dan akurat kepada pengambil keputusan dalam tataniaga (pemasaran) (Kotler dan Keller, 2007). 


\section{Analisis Keragaan Pasar}

Struktur dan Perilaku Pasar dapat menentukan Keragaan Pasar. Keragaan pasar dapat dilihat dari beberapa faktor diantaranya adalah Marjin tataniaga (pemasaran). Marjin tataniaga (pemasaran) dibuat berdasarkan lembaga dan saluran tataniaga (pemasaran) yang terjadi atau yang dilalui.

\section{Marjin Tataniaga (Pemasaran)}

Berdasarkan Saluran tataniaga (pemasaran) Ikan Cumi-cumi yang terjadi TPI KUD Mandiri Mina Fajar Sidik seperti yang terlihat pada Gambar 3, menunjukan bahwa sebagian besar Ikan Cumi-cumi (60 \%) dipasarkan melalui saluran tataniaga (pemasaran I), sedangkan saluran tataniaga (pemasaran) II dan III masing-masing sebesar (30\%) dan (10\%). Dari masing-masing saluran tataniaga (pemasaran) kemudian dihitung marjin tataniaga (pemasaran) nya. Cara yang digunakan untuk menghitung marjin adalah dengan mengurangi harga jual di tingkat konsumen dengan harga jual di tingkat produsen (TPI KUD Mandiri Mina Fajar Sidik). Saluran pada tataniaga (pemasaran) I yang merupakan saluran pemasaran yang jumlah pemasaran produk Ikan Cumi-cuminya paling banyak bila dibandingkan dengan saluran tataniaga (pemasaran) II dan III. Hal ini dikarenakan saluran tataniaga (pemasaran) I merupakan saluran tataniaga (pemasaran) yang paling panjang rantai saluran tataniaga (pemasaran). Dengan demikian jumlah/ volume produk Ikan Cumi-cumi yang dipasarkan melalui saluran tataniaga (pemasaran) I lebih banyak dibandingkan dengan saluran tataniaga (pemasaran) II dan III. Oleh karena itu, harga jual per kilogram yang ditawarkan oleh produsen (TPI KUD Mandiri Mina Fajar Sidik) kepada Supplier, Pedagang Pengecer, dan Exportir harganya sama yaitu Rp. 23.000,untuk semua saluran tataniaga (pemasaran), namun harga jual dari Supplier, Pedagang Pengecer, dan Exportir kepada konsumennya berbedabeda yaitu untuk saluran III Rp. 28.500,untuk saluran II dan I sama yaitu Rp. 27.000,-.

Marjin tataniaga (pemasaran) merupakan selisih harga yang dibayar konsumen akhir dengan harga yang diterima produsen. Marjin tataniaga (pemasaran) terdiri dari rincian biaya pemasaran dan keuntungan. Analisis marjin tataniaga (pemasaran) dilakukan untuk melihat besarnya penyebaran biaya dan keuntungan setiap lembaga tataniaga (pemasaran). Adapun marjin dan 
Tabel 3. Marjin dan Persentase Marjin pada Setiap Lembaga dan Saluran Tataniaga (Pemasaran) Ikan Cumi-cumi.

\begin{tabular}{|c|c|c|c|c|c|c|c|}
\hline \multirow[b]{2}{*}{ No } & \multirow[b]{2}{*}{$\begin{array}{c}\text { Lembaga Tataniaga } \\
\text { (Pemasaran) } \\
\& \\
\text { Komponen Marjin } \\
\end{array}$} & \multirow{2}{*}{$\begin{array}{c}\text { Saluran } 1 \\
\begin{array}{c}\text { Harga } \\
\text { Cumi-cumi } \\
(\mathbf{R p} / \mathrm{Kg})\end{array} \\
\end{array}$} & \multirow[b]{2}{*}{$\%$} & \multirow{2}{*}{$\begin{array}{c}\text { Saluran } 2 \\
\text { Harga } \\
\text { Cumi- } \\
\text { cumi } \\
(\mathbf{R p} / \mathbf{K g}) \\
\end{array}$} & \multirow{2}{*}{\multicolumn{2}{|c|}{$\begin{array}{c}\text { Saluran } 3 \\
\text { Harga } \\
\text { Cumi- } \\
\text { cumi } \\
(\mathbf{R p} / \mathbf{K g}) \\
\end{array}$}} & \multirow[b]{2}{*}{$\%$} \\
\hline & & & & & & & \\
\hline 1 & $\begin{array}{l}\text { Produsen (TPI KUD } \\
\text { MMFS) } \\
\text { Harga Jual : } \\
\text { Supplier : }\end{array}$ & 23.000,- & 85,1 & 23.000,- & 85,1 & 23.000,- & 85,1 \\
\hline 2 & $\begin{array}{ll}\text { - } & \text { Harga beli } \\
\text { - } & \text { Biaya pemasaran } \\
\text { - } & \text { Keuntungan } \\
\text { - } & \text { Marjin } \\
& \text { pengumpul } \\
\text { - } & \text { Harga jual }\end{array}$ & $\begin{array}{r}23.000,- \\
800,- \\
1200,- \\
2000,- \\
25.000\end{array}$ & $\begin{array}{r}85,1 \\
2,96 \\
4,8 \\
7,4 \\
92,6\end{array}$ & $\begin{array}{l}- \\
- \\
- \\
- \\
-\end{array}$ & $\begin{array}{l}- \\
- \\
- \\
-\end{array}$ & $\begin{array}{l}- \\
- \\
- \\
- \\
- \\
-\end{array}$ & $\begin{array}{l}- \\
- \\
-- \\
- \\
- \\
-\end{array}$ \\
\hline 3 & $\begin{aligned} & \text { Pedagangn Pengecer: } \\
& \text { - } \text { Harga beli } \\
&- \text { Biaya pemasaran } \\
&- \text { Keuntungan } \\
&- \text { Marjin } \\
&- \text { Harga jual }\end{aligned}$ & $\begin{array}{r}25.000,- \\
800,- \\
2700,- \\
3500,- \\
27.000,-\end{array}$ & $\begin{array}{r}92,6 \\
2,96 \\
10 \\
12,9 \\
100\end{array}$ & $\begin{array}{r}25.000,- \\
800,- \\
2700,- \\
3500,- \\
27.000,-\end{array}$ & $\begin{array}{r}92,6 \\
2,96 \\
10 \\
12,9 \\
100\end{array}$ & $\begin{array}{l}- \\
- \\
- \\
-\end{array}$ & $\begin{array}{l}- \\
- \\
- \\
-\end{array}$ \\
\hline 4 & $\begin{aligned} & \text { Ekportir : } \\
&- \text { Harga beli } \\
&- \text { Biaya pemasaran } \\
&- \text { Keuntungan } \\
&- \text { Marjin } \\
&- \text { Harga jual }\end{aligned}$ & $\begin{array}{l}- \\
- \\
- \\
- \\
-\end{array}$ & $\begin{array}{l}- \\
- \\
- \\
- \\
-\end{array}$ & $\begin{array}{l}- \\
- \\
- \\
- \\
-\end{array}$ & $\begin{array}{l}- \\
- \\
- \\
- \\
-\end{array}$ & $\begin{array}{r}23.000,- \\
3.000,- \\
2.500,- \\
5.500,- \\
28.500,-\end{array}$ & $\begin{array}{r}80,7 \\
10,5 \\
8,77 \\
19,3 \\
100\end{array}$ \\
\hline 5 & $\begin{array}{l}\text { Konsumen } \\
-\quad \text { Harga beli }\end{array}$ & $27.000,-$ & 100 & $27.000,-$ & 100 & $28.500,-$ & 100 \\
\hline
\end{tabular}

Sumber : Data Hasil Olahan, 2014

persentase untuk komoditi Ikan Cumicumi pada setiap lembaga dan saluran tataniaga (pemasaran) selengkapnya dapat dilihat pada Tabel 3. Berdasarkan data pada Tabel 3, suatu marjin tataniaga (pemasaran) untuk masing-masing saluran tataniaga (pemasaran) ternyata berbedabeda.

Lebih lanjut tergambarkan dari data Tabel 3, marjin tataniaga (pemasaran) untuk masing-masing saluran tataniaga (pemasaran) berbeda-beda tergantung pada saluran yang dilalui oleh produk Ikan
Cumi-cumi pada saluran pemasaran I dan II, besar marjin totalnya sama yaitu $\mathrm{Rp}$. $5.000,-/ \mathrm{kg}$ sedangkan pada saluran tataniaga (pemasaran) III marjin totalnya sebesar Rp. 5.500,-/kg. Lebih besarnya marjin tataniaga (pemasaran) pada saluran unit tataniaga (pemasaran) I dan II dibandingkan dengan saluran tataniaga (pemasaran) III ini disebabkan karena pada saluran tataniaga (pemasaran) III ini jarak lokasinya lebih jauh. Kondisi ini mengakibatkan biaya pemasaran menjadi lebih tinggi dan keuntungan yang diambil 
oleh pelaku-pelaku pasar tentunya juga akan semakin besar. Keadaan ini pada akhirnya mengakibatkan semakin besarnya marjin tataniaga (pemasaran).

Berdasarkan kondisi di atas, terlihat bahwa pada setiap Lembaga Tataniaga (Pemasaran) memiliki penyebaran marjin yang berbeda-beda (tidak merata/tidak adil), hal ini dikarenakan adanya perbedaan terhadap fungsi - fungsi pemasaran maupun komponen dari setiap fungsi pemasaran yang dilakukan. Penyebaran marjin yang berbeda-beda disebabkan karena banyaknya Lembaga Tataniaga (Pemasaran) yang terlibat dalam hal ini adalah TPI KUD Mandiri Mina Fajar Sidik, Supplier, dan Pedagang Pengecer. Akibat dari hal itu, maka banyak pula perlakuan yang diberikan terhadap komoditi Ikan Cumi-cumi, sehingga menimbulkan kenaikan biaya pemasaran dan kecendrungan untuk mendorong pengambilan keuntungan yang lebih besar oleh masing-masing lembaga tataniaga (pemasaran). Kondisi demikian menunjukkan bahwa sistem tataniaga (pemasaran) Ikan Cumi-cumi di TPI KUD Mandiri Mina Fajar Sidik dapat dianggap belum efisien, karena belum mampu mengadakan pembagian yang merata/adil dari keseluruhan harga yang dibayarkan oleh konsumen akhir kepada semua pihak yang terlibat dalam sistem pemasaran Ikan
Cumi-cumi tersebut. Menurut Hutabarat (1988), bahwa sistem tataniaga (pemasaran) dikatakan telah bekerja secara efisien atau pasar terpadu sempurna apabila harga yang dibayar oleh konsumen dan jumlah produk yang ditawarkan oleh produsen tidak berpengaruh terhadap marjin tataniaga (pemasaran) atau dengan kata lain persentase marjin tiap lembaga tataniaga (pemasaran) adalah tetap atau konstan.

\section{SIMPULAN DAN SARAN}

\section{Simpulan}

1. Strukur pasar yang berlaku di TPI KUD Mandiri Mina Fajar Sidik Desa Blanakan Kecamatan Blanakan Kabupaten Subanag Provinsi Jawa Barat adalah pasar persaingan tidak sempurna (imperfectly competition market). Hal ini dapat dilihat dari lembaga dan saluran tataniaga (pemasaran). Dari sisi lembaga tataniaga (pemasaran) hanya ada satu penjual yaitu TPI KUD Mandiri Mina Fajar Sidik sedangkan pembelinya lebih dari satu yaitu supplier, pedagang pengecer, dan exportir. Dari sisi saluran tataniaga (pemasaran) menunjukkan saluran tataniaga (pemasaran) yang panjang.

2. Berdasarkan struktur pasar di atas, maka keragaan pasar yang terjadi di TPI KUD Mandiri Mina Fajar Sidik 
adalah terjadinya penyebaran marjin yang berbeda-beda (tidak merata/tidak adil) dan nilai marjin yang tinggi. Penyebaran marjin yang berbeda-beda ini menunjukkan bahwa sistem tataniaga (pemasaran) Ikan Cumicumi yang terjadi di TPI KUD Mandiri Mina Fajar Sidik tidak efisien. Disamping itu marjin tataniaga (pemasaran) yang tinggi juga menunjukkan belum efisiensinya tataniaga (pemasaran) hal itu disebabkan oleh biaya pemasaran (yang tetap).

\section{Saran}

Berdasarkan kesimpulan diatas, disebutkan bahwa struktur pasar yang terjadi di TPI KUD Mandiri Mina Fajar Sidik adalah pasar persaingan tidak sempurna (imperfectly competition market) yang lebih mengarah kepada Struktur Pasar Monopoli. Hal ini dikarenakan hanya ada 1 produsen dalam hal ini adalah TPI KUD Mandiri Mina Fajar Sidik. Sebagaimana diketahui bahwa Pasar Monopoli lebih cenderung kepada penetapan harga sesuai dengan yang diinginkan. Tentunya hal ini dapat membuat sulit bagi pembeli karena penetapan harga terkadang tidak didasari atas harga pasar yang terjadi karena tidak adanya pesaing. Atas dasar tersebut maka disarankan kepada pihak TPI KUD
Mandiri Mina Fajar Sidik agar para nelayan yang berperan sebagai produsen diperbolehkan menjual kepada pedagang secara langsung dan tidak harus semua hasil tangkapannya dijual melalui TPI KUD Mandiri Mina Fajar Sidik.

\section{DAFTAR PUSTAKA}

Azzaino, 1983. Pengantar tataniaga pertanian. Departemen Ilmu-ilmu Sosial Ekonomi Pertanian. Fakultas Pertanian Institut Pertanian Bogor.

Dahl DA dan JW Hammond. 1977. Market and price analysis the agricultural industries. Mc Graw Hill, New York.

Koentjoroningrat. $1993 . \quad$ Metode Penelitian masyarakat. Gramedia Pustaka Utama, Jakarta.

Kohl RL and WD Downey. 1972. Marketing of agricultural product, fourth edition. The Macmillan Company, New York.

Kotler P dan G Amstrong. 1992. Dasardasar pemasaran (jilid 1 edisi 5). Intermedia, Jakarta.

Kotler P dan KL Keller. 2006. Manajemen pemasaran (jilid 1 edisi 12). Indeks, Jakarta.

Manulang M. 1994. Pengantar ekonomi perusahaan. Liberty, Yogyakarta.

Nasruddin W. 1999. Tataniaga pertanian. Universitas Terbuka, Jakarta.

Nurjanah, Leni Marlina dan Iriani Setyaningsih. 1999. kandungan logam $\mathrm{Hg}, \mathrm{Pb}, \mathrm{Cd}, \mathrm{Cu}$ dan As pada cumi-cumi dan sotong yang didaratkan di Tepi Muara Angka dan upaya penurunannya. Bulletin THP Vol VI (1): 9-13 
Omar S bin Andi. 2002. Biologi reproduksi cumi-cumi (Sepioteuthis lessoniana Lesson, 1830). Tesis Program Pascasarjana IPB. 237 hal.

Sudiyono, A. 2002. Pemasaran Pertanian. diterbitkan oleh Universitas Muhammadiyah Malang, Malang.

Tomek WG dan KL Robinson. 1977. Agricultural production and prices second edition. Cornell University Press, Ithaca. 
Lampiran 1. Karakteristik Pedagang Ikan Cumi-cumi di TPI KUD Mandiri Mina Fajar Sidik Desa. Blanakan Kecamatan Blanakan Kabupaten Subang

\begin{tabular}{|c|c|c|c|c|}
\hline No & $\begin{array}{l}\text { KARAKTERISTIK } \\
\text { PEDAGANG }\end{array}$ & VARIABEL PENELITIAN & $\begin{array}{c}\text { JML RESPONDEN } \\
\text { (ORG) }\end{array}$ & $\begin{array}{c}\text { PERSENTASE } \\
(\%)\end{array}$ \\
\hline \multirow{4}{*}{1.} & \multirow{4}{*}{ Umur } & a. 20-25 tahun & 3 & 30 \\
\hline & & b. 26-35 tahun & 4 & 40 \\
\hline & & c. $36-50$ tahun & 2 & 20 \\
\hline & & d. $>50$ tahun & 1 & 10 \\
\hline \multirow{3}{*}{2.} & \multirow{3}{*}{ Jenis Kelamin } & a. Laki-laki & 6 & 60 \\
\hline & & b. Perempuan & 4 & 40 \\
\hline & & a. 2 orang & - & - \\
\hline \multirow{5}{*}{3.} & \multirow{3}{*}{ Jumlah Keluarga } & b. 3 orang & - & - \\
\hline & & c. 4 orang & 4 & 40 \\
\hline & & d. $>4$ orang & 6 & 60 \\
\hline & & a. Tdk.pernah sekolah & 2 & 20 \\
\hline & & b. SD & 5 & 50 \\
\hline \multirow[t]{3}{*}{4.} & Tk. Pendidikan & c. SLTP & 2 & 20 \\
\hline & & d. SLTA & 1 & 10 \\
\hline & & e. Perguruan Tinggi & - & - \\
\hline \multirow{3}{*}{5.} & & a. Perorangan & 10 & 100 \\
\hline & Bentuk Usaha & b. Badan Usaha & - & - \\
\hline & & a. Ped. Pengumpul & 5 & 50 \\
\hline \multirow{4}{*}{6.} & & lokal/Supplier & 5 & 10 \\
\hline & Status Usaha & b. Ped.Besar/Eksportir & $\begin{array}{l}1 \\
4\end{array}$ & 40 \\
\hline & & c. Ped. Pengecer & 4 & \\
\hline & & a. $<5$ tahun & 4 & 40 \\
\hline \multirow{3}{*}{7.} & J ama Usaba & b. 5-10 tahun & 5 & 50 \\
\hline & Lama Usaha & c. 11-20 tahun & 1 & 10 \\
\hline & & d. $>20$ tahun & - & - \\
\hline \multirow{3}{*}{8.} & & a. Usaha Pokok & 10 & 100 \\
\hline & Orıentası Usaha & b. Usaha Sampingan & - & - \\
\hline & & a. $<50 \mathrm{~kg}$ & 5 & 50 \\
\hline \multirow[t]{3}{*}{9} & Volume Pembelian & b. $\quad 51-100 \mathrm{~kg}$ & 3 & 30 \\
\hline & & c. $101-500 \mathrm{~kg}$ & 2 & 20 \\
\hline & & a. Rp.15.000-Rp. 20.000 & - & - \\
\hline 10 & Harga Pembelian Cumi- & b. Rp.20.500-Rp. 25.000 & 9 & 90 \\
\hline 10 & cumi & c. Rp.25.500-Rp. 30.000 & 1 & 10 \\
\hline & & d. Rp.30.500-Rp. 35.000 & - & - \\
\hline & & a. TPI KUD MMFS & 10 & 100 \\
\hline & Sumber Ikan Cumı-cumı & b. Ped.Pengumpul Lokal & - & - \\
\hline 11 & & c. Ped.Besar/Eksportir & - & - \\
\hline & & d. Ped. Pengecer & - & - \\
\hline & Harga Penjualan Ikan Cumi- & a. Rp.15.000-Rp.20.000 & - & - \\
\hline 12 & Harga Penjualan IKan C um-- & c. b. Rp. $20.500-R p \cdot 25.000$ & - & - \\
\hline 12 & & d. Rp.25.500-Rp.30.000 & 9 & 90 \\
\hline & & e. Rp.30.500-Rp.35.000 & 1 & 10 \\
\hline & & a. Kontan & 10 & 100 \\
\hline 13 & Sistem Pembayaran & b. Kredit & - & - \\
\hline 13 & Penjualan Cumi-cumi & c. Komisi & - & - \\
\hline & & d. Lain-lain & - & - \\
\hline & & a. TPI KUD MMFS & 10 & 100 \\
\hline & & b. Ped.Pengumpul Lokal & - & - \\
\hline 14 & Cara Memperoleh Informası & c. Ped.Besar/Eksportir & - & - \\
\hline & & d. Ped. Pengecer & - & - \\
\hline & & e. Lain-lain & - & - \\
\hline & & a. Bebas memilih pembeli & 2 & 20 \\
\hline 15 & Sistem Penjualan Ikan & b. Terikat dengan pembeli & - & - \\
\hline 15 & Cumi-cumi & c. Langganan & 8 & 80 \\
\hline & & d. Lain-lain & - & - \\
\hline & Sumber Modal Biava & a. Modal sendiri & 10 & 100 \\
\hline 16 & Sumber Modal Biaya & b. Pinjaman Bank & - & - \\
\hline 16 & & c. Pinjaman Koperasi & - & - \\
\hline & & d. Lain-lain & - & - \\
\hline & & a. Biaya Pengemasan & - & - \\
\hline 17 & Biaya yang dikeluar-kan & b. Biaya Pengangkutan & 10 & 100 \\
\hline 17 & selama proses perdagangan & c. Biaya Penyimpanan & - & - \\
\hline & & d. Biaya lain-lain & - & - \\
\hline 18. & Bentuk Usaha & a. Perorangan & 10 & 100 \\
\hline & & b. Badan Usaha & - & - \\
\hline 19. & Status Usaha & a. Ped. Pengumpul lokal & 5 & 50 \\
\hline & & b. Ped.Besar/Eksportir & - & - \\
\hline & & c. Ped. Pengecer & 5 & 50 \\
\hline
\end{tabular}

